OPEN ACCESS

Edited by:

Song Yang,

Qingdao Agricultural University, China

Reviewed by:

Xuhua Mo,

Qingdao Agricultural University, China Kaifeng Du,

Sichuan University, China

*Correspondence:

Liping Wang

lipingw2006@163.com

Weiming Zhu

weimingzhu@ouc.edu.cn

${ }^{\dagger}$ These authors have contributed equally to this work

Specialty section:

This article was submitted to Microbial Physiology and Metabolism.

a section of the journal

Frontiers in Microbiology

Received: 18 January 2021 Accepted: 08 February 2021

Published: 25 February 2021

Citation:

Xu Y, Wang Y, Wu D, He W

Wang $L$ and Zhu W (2021) p-Terphenyls From Aspergillus $s p$.

GZWMJZ-055: Identification,

Derivation, Antioxidant

and $\alpha$-Glycosidase Inhibitory

Activities.

Front. Microbiol. 12:654963. doi: 10.3389/fmicb.2021.654963

\section{p-Terphenyls From Aspergillus sp. GZWMJZ-055: Identification, Derivation, Antioxidant and $\alpha$-Glycosidase Inhibitory Activities}

\author{
Yanchao $\mathrm{Xu}^{1,2,3+}$, Yong Wang ${ }^{1,2,3+}$, Dan Wu ${ }^{1,3}$, Wenwen He ${ }^{1,3}$, Liping Wang ${ }^{1,2,3 *}$ and \\ Weiming Zhu ${ }^{1,4 *}$ \\ 1 State Key Laboratory of Functions and Applications of Medicinal Plants, Guizhou Medical University, Guiyang, China, \\ ${ }^{2}$ School of Pharmaceutical Sciences, Guizhou Medical University, Guiyang, China, ${ }^{3}$ Key Laboratory of Chemistry for Natural \\ Products of Guizhou Province, Chinese Academy of Sciences, Guiyang, China, ${ }^{4}$ Laboratory for Marine Drugs \\ and Bioproducts, Pilot National Laboratory for Marine Science and Technology, School of Medicine and Pharmacy, Ocean \\ University of China, Qingdao, China
}

One new (1) and fifteen known (2-16) p-terphenyls were isolated from a solid culture of the endophytic fungus Aspergillus sp. GZWMJZ-055 by adding the leaves of its host Eucommia ulmoides. Furthermore, nine p-terphenyls (17-25) were synthesized from the main compounds (5-7), among which derivatives 18, 19, 21, 22, and 25 are new $p$-terphenyls. Compounds $\mathbf{1 5}$ and $\mathbf{1 6}$ were also, respectively, synthesized from compounds $\mathbf{6}$ and $\mathbf{7}$ by oxidative cyclization of air in the presence of silica gel. These $p$-terphenyls especially those with $4,2^{\prime}, 4^{\prime \prime}$-trihydroxy $(\mathbf{4 - 7}, \mathbf{2 0}, \mathbf{2 1})$ or $4,4^{\prime \prime}$ dihydroxy-1,2,1',2'-furan $(\mathbf{1 5}, \mathbf{1 6})$ substituted nucleus, exhibited significant antioxidant and $\alpha$-glucosidase inhibitory activities and lower cytotoxicity to caco- 2 cells. The results indicated their potential use as lead compounds or dietary supplements for treating or preventing the diabetes.

Keywords: endophytic fungus, Aspergillus sp., antioxidant activity, $\alpha$-glucosidase inhibition, Eucommia ulmoides

\section{INTRODUCTION}

Diabetes is a chronic metabolic disease characterized by high blood sugar (HBS). Long-term HBS causes the damage to blood vessels and endangers various organs such as the heart, brain, kidneys, peripheral nerves, and eyes, and thus seriously affects the life quality of patients. Studies show that oxidative stress may be one of the important causes for diabetes and its complications. Too much reactive oxygen species in the body will increase the maturation disorder and apoptosis of pancreatic $\beta$-cells, leading to decrease insulin synthesis and secretion. Hyperglycemia and hyperlipidemia in diabetic patients can promote the production of active oxides, causing oxidative stress, then oxidative stress and hyperglycemia promote each other, leading to a vicious circle (Karunakaran and Park, 2013). At present, the treatment of type 2 diabetes is based on oral drugs, mainly containing metformin, $\alpha$-glucosidase inhibitors, dipeptidyl peptidase IV inhibitors, and 
sodium-glucose cotransporter 2 inhibitors. Among them, $\alpha$-glucosidase inhibitors can inhibit the degradation of polysaccharides to glucose and delay the absorption of glucose in the small intestine to reduce blood sugar. Such drugs can effectively reduce postprandial hyperglycemia without causing symptoms of hypoglycemia and are highly beneficial to patients who use carbohydrates as their main source of calories.

The $\alpha$-glucosidase inhibitors, such as acarbose, miglitol, and voglibose currently used clinically are all microbial metabolites or their derivatives. Therefore, discovery of the new $\alpha$-glucosidase inhibitors from microbial natural products (NPs) has unique advantages. $p$-Terphenyls, as an important kind of fungal NPs, its chemical investigation could be dated back to 1877 (Liu, 2006). At present, over 230 p-terphenyls have been isolated from fungi and lichens ( $\mathrm{Li}$ et al., 2018). In addition, some p-terphenyl derivatives were also total synthesized (Yonezawa et al., 1998; Takahashi et al., 2017; Zhang et al., 2018). As reported, p-terphenyls had a broad spectrum of biological properties, such as cytotoxic (Wang et al., 2019, 2020), antimicrobial (Intaraudom et al., 2017), and phosphodiesterase inhibitory (El-Elimat et al., 2013) activities, but the most interesting bioactivities were antioxidative (Kuhnert et al., 2015) and $\alpha$ glucosidase inhibitory activities (Ma et al., 2014). Furthermore, p-terphenyls can also be isolated from edible mushroom (Liu et al., 2004; Ma et al., 2014; Wang et al., 2014), indicating that this kind of compounds have low toxicity in the human body and are very suitable for the research of anti-diabetic drugs.

During our research for new compounds with $\alpha$-glucosidase inhibitory activity from the plant endophytes, we isolated and identified a $p$-terphenyls-producing strain, Aspergillus sp. GZWMJZ-055 endophytic with the famous Chinese medical plant Eucommia ulmoides. The fermentation potency (5.3$9.5 \mathrm{~g} / \mathrm{kg}$ ) and the $\alpha$-glucosidase inhibitory activity ( $\mathrm{IC}_{50}$ 15.0 to $2.0 \mu \mathrm{g} / \mathrm{mL}$ ) of the ethyl acetate (EtOAc) extracts of the fermentation significantly increased after adding the leaves of Eucommia ulmoides to the culture medium (Figure 1). Chemical investigation led to the isolation of sixteen $p$-terphenyls, including the new 3-O-methyl- $4^{\prime \prime}$ deoxyterprenin (1) as well as the known 4-deoxyterphenyllin (2) (Lin et al., 2019), 4" -deoxy-2'-methoxyterphenyllin (3) (Shan et al., 2019), $5^{\prime}$-methoxy- $\left[1,1^{\prime}: 4^{\prime}, 1^{\prime \prime}\right.$-terphenyl $]-2^{\prime}, 3^{\prime}, 4,4^{\prime \prime}$ tetraol (4) (Zhang et al., 2018), terphenyllin (5) (Kamigauchi et al., 1998), 3-hydroxyterphyllin (6) (Liu et al., 2012), 3,3" dihydroxyterphyllin (7) (Liu et al., 2012), 4"-deoxyterphenyllin (8) (Shan et al., 2019), 4"-deoxy-3-hydroxyterphenyllin (9) (Wang et al., 2020), 3'-O-methylterphenyllin (10) (Yan et al., 2017), 4"-deoxyprenylterphenyllin (11) (Wei et al., 2007), prenylterphenyllin A (12) (Cai et al., 2011), 3-methoxyterprenin (13) (Kamigauchi et al., 1998), 4"-deoxycandidusin A (14) (Guo et al., 2012), candidusin A (15) (Wang et al., 2020), and candidusin B (16) (Liu et al., 2012; Figure 2). Compounds 15 and 16 were also, respectively, prepared from compounds 6 and 7 by an intramolecular oxidative cyclization of air catalyzed by silica gel (Scheme 1). In addition, nine $p$-terphenyls (17-25) were synthesized from the main NPs (5-7) (Scheme 1), among which derivatives 18, 19, 21, 22, and 25 are new $p$-terphenyls. These $p$-terphenyls showed antioxidant and $\alpha$-glycosidase inhibitory activities (Table 1).

\section{MATERIALS AND METHODS}

\section{General Experimental Procedures}

UV spectra were measured on a Waters 2487 dual $\lambda$ absorbance detector. IR spectra were recorded on a Nicolet Nexus 470 spectrophotometer as $\mathrm{KBr}$ disks. ${ }^{1} \mathrm{H},{ }^{13} \mathrm{C}$ NMR and $2 \mathrm{D} \mathrm{NMR}$ spectra were recorded on Bruker-600 $\mathrm{MHz}$ using TMS as an internal standard. ESIMS and HR-ESIMS analysis were carried out on Waters Xevo TQS and Agilent Technologies 6530 Accurate-Mass Q-TOF LC/MS, respectively. Column chromatography was performed on silica gel (200-300 mesh; Qingdao Puke Parting Materials Co., Ltd., China), Sephadex LH-20 (Amersham Biosciences, Uppsala, Sweden), silica gel $\mathrm{H}$, and plates precoated with silica gel GF254 (Qingdao Puke Parting Materials Co., Ltd., China), respectively. HPLC separation was performed on HITACHI Primaide with an ODS column (YMC-pack ODS-A, $10 \mathrm{~mm} \times 250 \mathrm{~mm}, 5 \mu \mathrm{m}$, $4 \mathrm{~mL} / \mathrm{min}$ ). Synthetic compounds were also purified using a SepaBean machine equipped with SepaFlash columns (Santai Technologies Inc., China).

\section{Fungal Material}

The fungus Aspergillus sp. GZWMJZ-055 was isolated from the leaves of Eucommia ulmoides collected from Guiyang Medicinal Botanical Garden and was determined as Aspergillus sp. by the phylogenetic tree (Supplementary Figure 1) of the ITS sequence (GenBank No. KY038594). The strain was deposited in Guiyang laboratory in $20 \%$ glycerol at $-80^{\circ} \mathrm{C}$.

\section{Cultural Media}

The working strain was prepared on PDA agar medium, containing $20 \%$ potato, $2.0 \%$ glucose, $2.0 \%$ agar, and $1 \mathrm{~L}$ tap water. The seed medium contained $2.0 \%$ maltose, $2.0 \%$ mannitol, $1.0 \%$ glucose, $1.0 \%$ sodium glutamate, $0.3 \%$ yeast extract, $0.1 \%$ corn extract, $0.1 \% \mathrm{KH}_{2} \mathrm{PO}_{4}, 0.05 \% \mathrm{MgSO}_{4} \cdot 7 \mathrm{H}_{2} \mathrm{O}, 1 \mathrm{~L}$ tap water. The solid fermentation medium was prepared from $100 \mathrm{~g}$ rice, $1 \mathrm{~g}$ dry leaves of Eucommia ulmoides and $120 \mathrm{~mL}$ distilled water in a 1000-mL Erlenmeyer flask.

\section{Fermentation, Extraction and Isolation}

The fungal strain GZWMJZ-055 was cultured on PDA at $28^{\circ} \mathrm{C}$ for 3 days to prepare the seed culture. Spores were incubated at $28^{\circ} \mathrm{C}$ for 2 days, a rotary shaker with shaking at $120 \mathrm{rpm}$ in a $500 \mathrm{~mL}$ cylindrical flask containing $150 \mathrm{~mL}$ seed medium. The seed medium $(5 \mathrm{~mL})$ was added to the above rice fermentation medium in a 1000-mL Erlenmeyer flask. Totally, 100 Erlenmeyer flasks were incubated at room temperature (rt) under static conditions for 30 days. The cultures were then extracted by ethyl acetate (EtOAc) (500 $\mathrm{mL}$ for each) three times and the combined EtOAc extracts were dried in vacuo until constant weigh to yield $423.5 \mathrm{~g}$ of EtOAc extract.

The EtOAc extract (423.5 g, adsorbed in $500 \mathrm{~g} \mathrm{100-200} \mathrm{mesh}$ silica gel) was chromatographed on a silica gel (2 kg, 200-300 


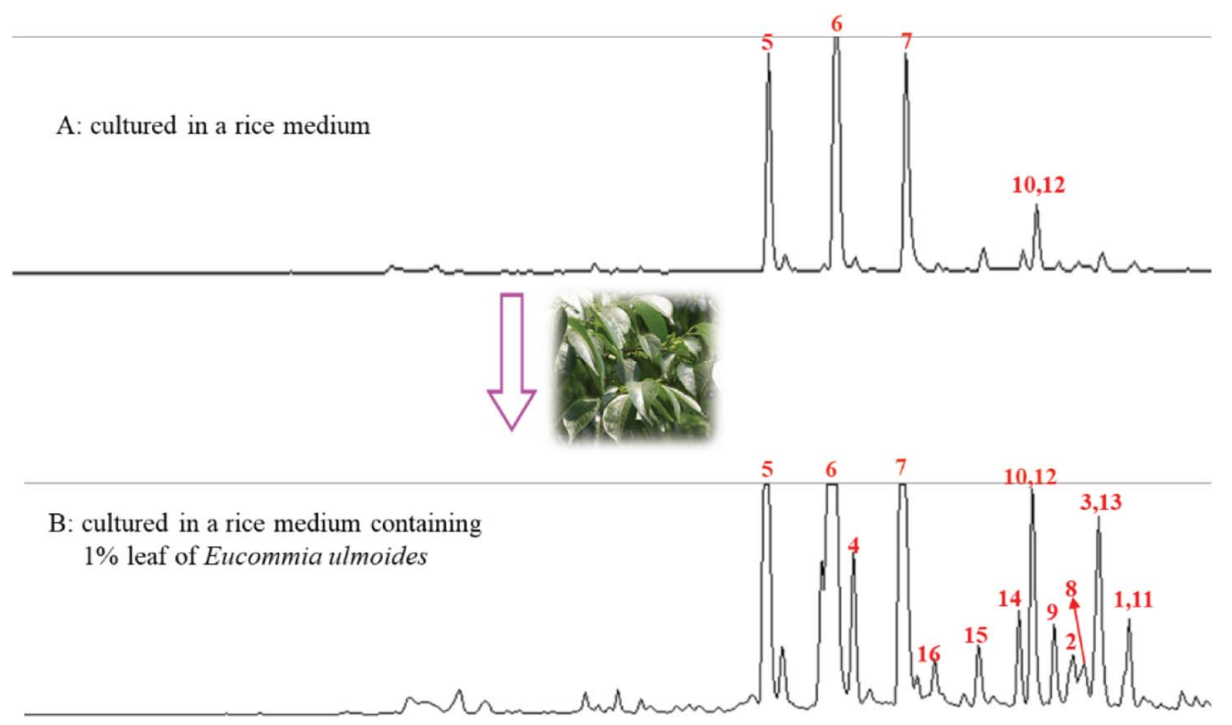

FIGURE 1 | HPLC Analysis of EtOAc extract from the rice cultures without $(\mathbf{A})$ and within $\mathbf{( B )}$ the leaf of E. ulmoides.

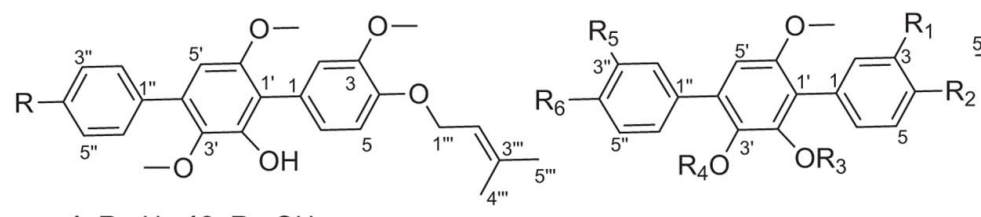

1: $\mathrm{R}=\mathrm{H}, 13: \mathrm{R}=\mathrm{OH}$<smiles>[R]c1ccc([C]2C=C(OC)[Z1]3c(oc4cc(O)c(O)cc34)=C2OC)cc1[R]</smiles>

14: $R_{1}=R_{2}=H$

15: $\mathrm{R}_{1}=\mathrm{H}, \mathrm{R}_{2}=\mathrm{OH}$

16: $\mathrm{R}_{1}=\mathrm{R}_{2}=\mathrm{OH}$
2: $R_{1}=R_{2}=R_{3}=R_{5}=H, R_{4}=M e, R_{6}=O H$

3: $R_{1}=R_{5}=R_{6}=H, R_{2}=O H, R_{3}=R_{4}=M e$

4: $\mathrm{R}_{1}=\mathrm{R}_{3}=\mathrm{R}_{4}=\mathrm{R}_{5}=\mathrm{H}, \mathrm{R}_{2}=\mathrm{R}_{6}=\mathrm{OH}$

5: $R_{1}=R_{3}=R_{5}=H, R_{2}=R_{6}=O H, R_{4}=M e$

6: $\mathrm{R}_{1}=\mathrm{R}_{2}=\mathrm{R}_{6}=\mathrm{OH}, \mathrm{R}_{3}=\mathrm{R}_{5}=\mathrm{H}, \mathrm{R}_{4}=\mathrm{Me}$

7: $R_{1}=R_{2}=R_{5}=R_{6}=O H, R_{3}=H, R_{4}=M e$

8: $R_{1}=R_{3}=R_{5}=R_{6}=H, R_{2}=O H, R_{4}=M e$

9: $R_{1}=R_{2}=O H, R_{3}=R_{5}=R_{6}=H, R_{4}=M e$

10: $R_{1}=R_{5}=H, R_{2}=R_{6}=O H, R_{3}=R_{4}=M e$<smiles>COc1cc(-c2ccc(O)c([CH+]C=C(C)C)c2)c(OC)c(O)c1-c1ccc(O)c(O)c1</smiles>

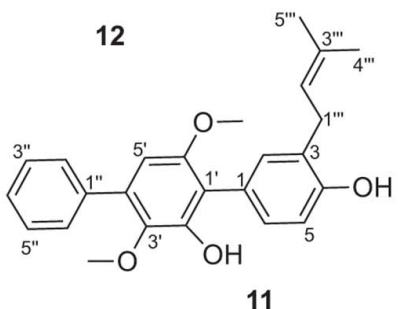

FIGURE 2 | The structures of compounds 1-16.

mesh) column $(10 \mathrm{~cm} \times 100 \mathrm{~cm})$ using step gradient elution of $\mathrm{CH}_{2} \mathrm{Cl}_{2}-\mathrm{MeOH}$ (v/v100:0, 100:1, 50:1, 25:1, 10:1, 5:1, 1:1, $1: 2,1: 5$, and 1:10, each $8 \mathrm{~L}$ ) to yield fifteen fractions (Fr.1Fr.15). Fraction 2 (18.7 g, adsorbed in $50 \mathrm{~g}$ 100-200 mesh silica gel) was then subjected to a silica gel (400 g, 200-300 mesh) column $(6 \mathrm{~cm} \times 61 \mathrm{~cm})$, eluting with $\mathrm{CH}_{2} \mathrm{Cl}_{2}-\mathrm{MeOH}$ (100:1, $\mathrm{v} / \mathrm{v})$ to afford sixteen subfractions (Fr.2-1 $\sim$ Fr.2-16). Subfraction Fr.2-3 (1.2 g) was separated with silica gel chromatography eluted by $\mathrm{CH}_{2} \mathrm{Cl}_{2}$ to yield five fractions (Fr.2-3-1 Fr.2-3-5). Subfraction Fr.2-3-4 (100.6 mg) was purified by semi-preparative HPLC [ $80 \% \mathrm{MeOH} / \mathrm{H}_{2} \mathrm{O}$ with $0.15 \%$ trifluoroacetic acid (TFA)] to yield compound $\mathbf{1}\left(17.2 \mathrm{mg}, \mathrm{t}_{R} 14.0 \mathrm{~min}\right)$. Fraction 2-7 (2.8 g) was further separated into six subfractions by Sephadex LH20 eluting with $\mathrm{MeOH}-\mathrm{CH}_{2} \mathrm{Cl}_{2}$ (1:1, v/v). Subfraction 2-7-4 $(455.0 \mathrm{mg})$ was separated with silica gel chromatography eluted by $\mathrm{CH}_{2} \mathrm{Cl}_{2}$ to yield three fractions (Fr.2-7-4-1 $\sim$ Fr.2-7-4-3). Subfraction 2-7-5 $(58.8 \mathrm{mg})$ was purified by semi-preparative
HPLC $\left(80 \% \mathrm{MeOH} / \mathrm{H}_{2} \mathrm{O}\right)$ to yield compound 11 (9.7 mg, $\left.\mathrm{t}_{R} 13.6 \mathrm{~min}\right)$. Fraction $2-9(185 \mathrm{mg})$ was further separated into five subfractions (Fr.2-9-1 Fr.2-9-5) by Sephadex LH-20 eluting with $\mathrm{MeOH}-\mathrm{CH}_{2} \mathrm{Cl}_{2}(1: 1, \mathrm{v} / \mathrm{v})$. Subfraction 2-9-3 separated with silica gel chromatography eluted by $\mathrm{CH}_{2} \mathrm{Cl}_{2}$ to yield five fractions (Fr.2-9-3-1 Fr.2-9-3-5). Fr.2-9-3-5 was further purified by semi-preparative HPLC $\left(80 \% \mathrm{MeOH} / \mathrm{H}_{2} \mathrm{O}\right)$ to yield compound 14 (5.6 $\left.\mathrm{mg}, \mathrm{t}_{R} 7.0 \mathrm{~min}\right)$. Subfraction 2-9-5 was purified by semi-preparative HPLC $\left(70 \% \mathrm{MeOH} / \mathrm{H}_{2} \mathrm{O}\right)$ to yield compound $12\left(6.0 \mathrm{mg}, \mathrm{t}_{R} 7.2 \mathrm{~min}\right)$. Fraction $2-13(240.2 \mathrm{mg})$ was further separated into fourteen subfractions by Sephadex LH-20 eluting with $\mathrm{MeOH}-\mathrm{CH}_{2} \mathrm{Cl}_{2}(1: 1, \mathrm{v} / \mathrm{v})$. Subfraction 2-13-10 was further separated into four subfractions separated with silica gel chromatography eluted by $\mathrm{MeOH}-\mathrm{CH}_{2} \mathrm{Cl}_{2}$ (1:80, v/v). Fr.2-13$10-2$ was purified by semi-preparative HPLC $\left(75 \% \mathrm{MeOH} / \mathrm{H}_{2} \mathrm{O}\right)$ to yield compound $3\left(12.5 \mathrm{mg}, \mathrm{t}_{R} 10.0 \mathrm{~min}\right)$. Subfraction 2-1313 was purified by semi-preparative $\mathrm{HPLC}\left(70 \% \mathrm{MeOH} / \mathrm{H}_{2} \mathrm{O}\right)$ to 
<smiles>[R]c1cc(-c2cc(OC)c3c(oc4cc(O)c(O)cc43)c2OC)ccc1O</smiles>

15: $\mathrm{R}=\mathrm{H}, 16: \mathrm{R}=\mathrm{OH}$<smiles>[R]c1cc(-c2cc(O)c(-c3ccc(O)c([R])c3)c(O)c2O)ccc1O</smiles>

17: $\mathrm{R}_{1}=\mathrm{R}_{2}=\mathrm{H}$

18: $\mathrm{R}_{1}=\mathrm{OH}, \mathrm{R}_{2}=\mathrm{H}$

19: $\mathrm{R}_{1}=\mathrm{R}_{2}=\mathrm{OH}$

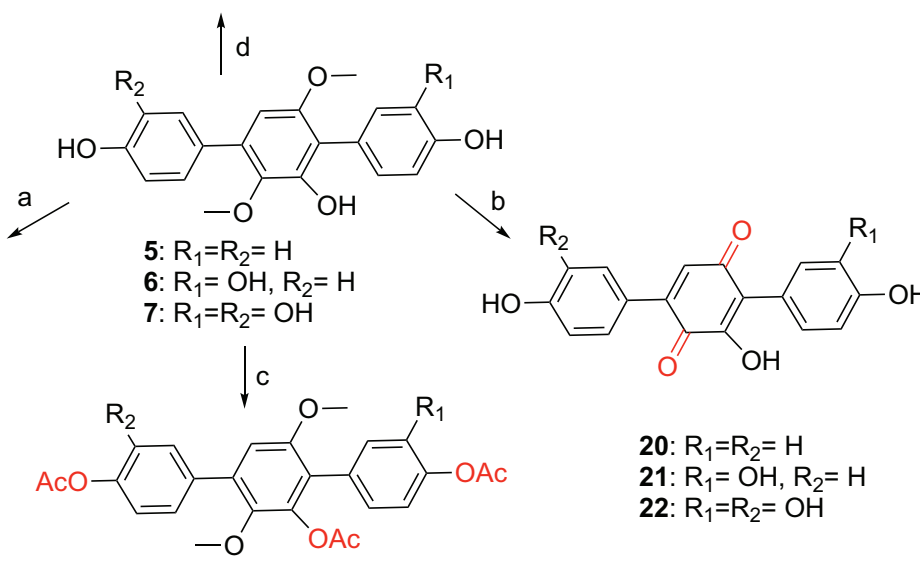

23: $\mathrm{R}_{1}=\mathrm{R}_{2}=\mathrm{H}$

24: $R_{1}=O A c, R_{2}=H$

25: $R_{1}=R_{2}=O A C$

SCHEME 1 | Synthesis of compounds 15-25 from 5 to 7 (a. $\mathrm{BBr}_{3} / \mathrm{CH}_{2} \mathrm{Cl}_{2},-20^{\circ} \mathrm{C}$ to rt; b. $\mathrm{BBr}_{3} / \mathrm{CH}_{2} \mathrm{Cl}_{2},-20^{\circ} \mathrm{C}$ to rt, then $\mathrm{O}_{2} /$ silica gel/MeOH; c. Ac $\mathrm{O}$, DMAP, $\mathrm{CH}_{2} \mathrm{Cl}_{2}, 40^{\circ} \mathrm{C}$; d. $\mathrm{O}_{2} /$ silica gel/MeOH, rt).

yield compound 2 (7.1 mg, $\left.\mathrm{t}_{R} 8.7 \mathrm{~min}\right)$. Fraction $2-14(452.3 \mathrm{mg})$ was further separated into six subfractions separated with silica gel chromatography eluted by $\mathrm{CH}_{2} \mathrm{Cl}_{2}$. Fr.2-14-5 (20.6 mg) was purified by semi-preparative HPLC $\left(80 \% \mathrm{MeOH} / \mathrm{H}_{2} \mathrm{O}\right)$ to yield compound $13\left(6.1 \mathrm{mg}, \mathrm{t}_{R} 16.0 \mathrm{~min}\right)$. Fraction 9 (3.5 g) was subjected to a silica gel column, elution with step gradient elution of $\mathrm{CH}_{2} \mathrm{Cl}_{2}-\mathrm{MeOH}(0-100 \%$, v/v) to afford three subfractions (Fr.9-1 Fr.9-3). Fraction 9-2 (1.2 g) was further separated into nine subfractions by Sephadex LH-20 eluting with $\mathrm{MeOH}$. Fraction 9-2-3 (418.2 mg) was further separated into seven subfractions separated with silica gel chromatography eluted by $\mathrm{MeOH}-\mathrm{CH}_{2} \mathrm{Cl}_{2}(1: 20, \mathrm{v} / \mathrm{v})$. Fraction 9-2-3-2 (20.0 mg) was purified by HPLC on an ODS column $\left(75 \% \mathrm{MeOH} / \mathrm{H}_{2} \mathrm{O}\right)$ to give compound 8 (4.0 $\left.\mathrm{mg}, \mathrm{t}_{R} 8.0 \mathrm{~min}\right)$. Fraction $9-2-3-5(26.1 \mathrm{mg})$ was purified by HPLC on an ODS column $\left(75 \% \mathrm{MeOH} / \mathrm{H}_{2} \mathrm{O}\right)$ to give compound 9 (6.4 $\mathrm{mg}, \mathrm{t}_{R} 4.5 \mathrm{~min}$ ). Fraction 9-2-9 (29.7 mg) was purified by HPLC on an ODS column $(65 \%$ $\left.\mathrm{MeOH} / \mathrm{H}_{2} \mathrm{O}\right)$ to give compound $15\left(6.1 \mathrm{mg}, \mathrm{t}_{R} 5.0 \mathrm{~min}\right)$. Fraction 9-3 (1.3 g) was further separated into thirteen subfractions by Sephadex LH-20 eluting with MeOH. Fraction 9-3-7 (317.1 mg) was further separated into nine subfractions separated with silica gel chromatography eluted by $\mathrm{MeOH}-\mathrm{CH}_{2} \mathrm{Cl}_{2}(1: 10$, v/v). Fraction 9-3-7-4 (10.7 mg) was purified by HPLC on an ODS column $\left(55 \% \mathrm{MeOH} / \mathrm{H}_{2} \mathrm{O}\right)$ to give compound $10\left(2.8 \mathrm{mg}, \mathrm{t}_{R}\right.$ $18.2 \mathrm{~min})$. Fraction 9-3-8 was further separated with silica gel chromatography eluted by $\mathrm{MeOH}-\mathrm{CH}_{2} \mathrm{Cl}_{2}(1: 15, \mathrm{v} / \mathrm{v})$ to get compound 5 (900 mg). Fraction 9-3-12 (52.7 mg) was purified by HPLC on an ODS column $\left(60 \% \mathrm{MeOH} / \mathrm{H}_{2} \mathrm{O}\right)$ to give compounds 4 (6.6 mg, $\left.\mathrm{t}_{R} 10.4 \mathrm{~min}\right)$ and $16\left(6.0 \mathrm{mg}, \mathrm{t}_{R} 18.0 \mathrm{~min}\right)$. Fraction
10 (2.8 g) was chromatographed on a silica gel column using step gradient elution of $\mathrm{CH}_{2} \mathrm{Cl}_{2}-\mathrm{MeOH}(5-100 \%$, v/v) to yield compounds 6 (700 $\mathrm{mg}$ ) and 7 (1.2 g).

Compound 1: white powder; UV $(\mathrm{MeOH}) \lambda_{\max }(\log \varepsilon) 230$ (4.03), 276 (3.96) nm; IR (KBr) $v_{\max } 3486,2934,1517,1482,1461$, $1399,1238,1117,1075,1009,770$, and $703 \mathrm{~cm}^{-1}$; HR ESIMS $m / z \quad 443.1837{ }^{[\mathrm{M}+\mathrm{Na}]^{+}}$(calcd. for $\mathrm{C}_{26} \mathrm{H}_{28} \mathrm{O}_{5} \mathrm{Na}, 443.1829$ ) (Supplementary Figure 2); ${ }^{1} \mathrm{H}$ and ${ }^{13} \mathrm{C}$ NMR data, see Table 2 and Supplementary Figures 3-7.

\section{Chemical Synthesis Procedures Synthesis of Compounds 15 and 16}

Compound 6 (30 mg, $85 \mu \mathrm{mol})$ was dissolved in $\mathrm{MeOH}(10 \mathrm{~mL})$, and 200-300 mesh silica gel (4 g) was then added to the solution. After the reaction was stirred overnight at $\mathrm{rt}$, the solvent was evaporated. The residue was purified by flash column chromatography (FCC) eluting with EtOAc- $\mathrm{CH}_{2} \mathrm{Cl}_{2}$ (v/v 1:5) to give compound $\mathbf{1 5}(26 \mathrm{mg}, 74 \mu \mathrm{mol}, 87 \%$ yield) as a lightyellow solid $\left(R_{f} 0.4\right)$. By the same procedure, compound 16 (24 mg, $65 \mu \mathrm{mol}, 80 \%$ yield) was prepared from the reaction of compound 7 (30 mg, $81 \mu \mathrm{mol}$ ) and purified as a light-yellow solid $\left(R_{f} 0.4\right)$ by FCC eluting with EtOAc- $\mathrm{CH}_{2} \mathrm{Cl}_{2}$ (v/v $\left.1: 3\right)$.

Compound 15: ${ }^{1} \mathrm{H}$ NMR (600 MHz, DMSO- $\left.d_{6}\right)$ and ${ }^{13} \mathrm{C} \mathrm{NMR}$ $\left(150 \mathrm{MHz}, \mathrm{DMSO}-d_{6}\right)$ data, see Supplementary Table 5 and Supplementary Figures 8, 9. ESIMS $m / z 351.0[\mathrm{M}-\mathrm{H}]^{-}$.

Compound 16: ${ }^{1} \mathrm{H}$ NMR (600 MHz, DMSO- $\left.d_{6}\right)$ and ${ }^{13} \mathrm{C}$ NMR (150 MHz, DMSO- $d_{6}$ ) data, see Supplementary Table 5 and Supplementary Figures 10, 11. ESIMS $m / z$ 367.1 $[\mathrm{M}-\mathrm{H}]^{-}$. 
TABLE 1 | Antioxidant and $\alpha$-glycosidase activities of compounds 1-25.

\begin{tabular}{|c|c|c|c|c|}
\hline Compound & DPPH $\left(\mathrm{IC}_{50}, \mu \mathrm{M}\right)$ & ORAC ( $\mu$ mole TE $/ \mu$ mole) & $\alpha$-glucosidase $\left(\mathrm{IC}_{50}, \mu \mathrm{M}\right)$ & $\alpha$-glucosidase in caco-2 $\left(\mathrm{IC}_{50}, \mu \mathrm{M}\right)$ \\
\hline 2 & $>100$ & $1.2 \pm 0.09$ & $239.1 \pm 5.9$ & - \\
\hline 4 & $1.7 \pm 0.02$ & $6.8 \pm 0.05$ & $5.9 \pm 0.6$ & - \\
\hline 5 & $10.9 \pm 0.3$ & $6.0 \pm 0.09$ & $2.8 \pm 0.2$ & $0.38 \pm 0.01$ \\
\hline 6 & $1.4 \pm 0.01$ & $5.7 \pm 0.3$ & $10.9 \pm 1.3$ & $0.29 \pm 0.02$ \\
\hline 8 & $57.8 \pm 0.8$ & $0.5 \pm 0.01$ & $129.8 \pm 3.5$ & - \\
\hline 9 & $1.9 \pm 0.04$ & $0.5 \pm 0.06$ & $464.5 \pm 23.6$ & - \\
\hline 10 & $>100$ & $0.5 \pm 0.03$ & $>500$ & - \\
\hline 11 & $1.6 \pm 0.01$ & $1.2 \pm 0.5$ & $34.4 \pm 1.1$ & - \\
\hline 12 & $1.6 \pm 0.02$ & $1.4 \pm 0.01$ & $64.4 \pm 1.2$ & - \\
\hline 13 & $>100$ & $0.4 \pm 0.07$ & $152.5 \pm 9.6$ & - \\
\hline 17 & $5.3 \pm 0.06$ & $4.8 \pm 0.3$ & $25.1 \pm 0.7$ & - \\
\hline 18 & $3.7 \pm 0.07$ & $3.7 \pm 0.1$ & $25.0 \pm 0.8$ & - \\
\hline 19 & $1.8 \pm 0.04$ & $2.6 \pm 0.1$ & $19.4 \pm 0.1$ & - \\
\hline 20 & $5.9 \pm 0.08$ & $6.1 \pm 0.2$ & $8.9 \pm 0.4$ & $0.11 \pm 0.01$ \\
\hline 21 & $1.6 \pm 0.04$ & $3.9 \pm 0.1$ & $4.0 \pm 0.08$ & $0.12 \pm 0.01$ \\
\hline 22 & $1.7 \pm 0.02$ & $2.8 \pm 0.3$ & $10.1 \pm 0.1$ & - \\
\hline 23 & $>100$ & $0.1 \pm 0.01$ & $>500$ & - \\
\hline 24 & $37.8 \pm 0.1$ & $0.8 \pm 0.07$ & $>500$ & - \\
\hline 25 & $11.0 \pm 0.1$ & $1.7 \pm 0.07$ & $>500$ & - \\
\hline vc & $2.8 \pm 0.03$ & & & \\
\hline Acarbose & & & $265.4 \pm 10.2$ & $157.7 \pm 14.0$ \\
\hline
\end{tabular}

- not tested.

\section{Synthesis of Compounds 17-19}

Compound 5 (30 mg, $89 \mu \mathrm{mol})$ was dissolved in $\mathrm{CH}_{2} \mathrm{Cl}_{2}(5 \mathrm{~mL})$, and $\mathrm{BBr}_{3}\left(0.8 \mathrm{~mL}, 0.54 \mathrm{mmol}, 17 \%\right.$ in $\left.\mathrm{CH}_{2} \mathrm{Cl}_{2}\right)$ was then added at $-20^{\circ} \mathrm{C}$ under the protection of argon. The reaction mixture was warmed up to $\mathrm{rt}$ and stirred overnight. The reaction was quenched by adding $\mathrm{H}_{2} \mathrm{O}(20 \mathrm{~mL})$ at $0^{\circ} \mathrm{C}$, and EtOAc $(200 \mathrm{~mL})$ was then added. The EtOAc phase was washed with $\mathrm{H}_{2} \mathrm{O}$ $(20 \mathrm{~mL} \times 4)$, dried over anhydrous $\mathrm{Na}_{2} \mathrm{SO}_{4}$, and concentrated in vacuo. The residue was purified by semipreparative HPLC eluting with $40 \% \mathrm{MeOH} / \mathrm{H}_{2} \mathrm{O}$ containing $0.15 \%$ TFA to provide compound 17 (26 mg, $84 \mu \mathrm{mol}, 94 \%$ yield, $t_{R} 7.5 \mathrm{~min}$ ) as an orange solid. By the same procedures, compound $18(25 \mathrm{mg}$, $77 \mu \mathrm{mol}, 91 \%$ yield, $t_{R} 8 \mathrm{~min}$ ) was prepared from the reaction of compound $6(30 \mathrm{mg}, 85 \mu \mathrm{mol})$ and $\mathrm{BBr}_{3}(0.76 \mathrm{~mL}, 0.51 \mathrm{mmol})$ in $\mathrm{CH}_{2} \mathrm{Cl}_{2}$ and purified from $\mathrm{HPLC}$ by $30 \% \mathrm{MeOH} / \mathrm{H}_{2} \mathrm{O}$ containing $0.15 \%$ TFA, while compound 19 (25 mg, $73 \mu \mathrm{mol}, 90 \%$ yield, $t_{R}$ $7 \mathrm{~min})$ was prepared from the reaction of $7(30 \mathrm{mg}, 81 \mu \mathrm{mol})$ and $\mathrm{BBr}_{3}(0.72 \mathrm{~mL}, 0.48 \mathrm{mmol})$ in $\mathrm{CH}_{2} \mathrm{Cl}_{2}$ and purified from HPLC by $25 \% \mathrm{MeOH} / \mathrm{H}_{2} \mathrm{O}$ containing $0.15 \%$ TFA.

Compound 17: ${ }^{1} \mathrm{H}$ NMR (600 MHz, DMSO- $\left.d_{6}\right)$ and ${ }^{13} \mathrm{C} \mathrm{NMR}$ (150 MHz, DMSO- $d_{6}$ ) data, see Supplementary Table 6 and Supplementary Figures 12, 13. ESIMS $m / z 309.2[\mathrm{M}-\mathrm{H}]^{-}$.

Compound 18: IR (KBr) $v_{\max } 3122,2355,2337,1714$, $1653,1504,1392,1236,1109,1030,827,671 \mathrm{~cm}^{-1}$. HR
ESIMS $m / z 325.0716[\mathrm{M}-\mathrm{H}]^{-}$(calcd. for $\mathrm{C}_{18} \mathrm{H}_{13} \mathrm{O}_{6}, 325.0707$ ) (Supplementary Figure 14). ${ }^{1} \mathrm{H}$ NMR $\left(600 \mathrm{MHz}, \mathrm{DMSO}-d_{6}\right)$ and ${ }^{13} \mathrm{C}$ NMR (150 MHz, DMSO- $\left.d_{6}\right)$ data, see Table 2 and Supplementary Figures 15, 16.

Compound 19: IR (KBr) $\nu_{\max } 3134,2357,2339,1682,1653$, $1556,1508,1456,1279,1184,1107,1032,872,667 \mathrm{~cm}^{-1}$. HRESI MS $m / z$ 343.0808 $[\mathrm{M}+\mathrm{H}]^{+}$(calcd. for $\mathrm{C}_{18} \mathrm{H}_{15} \mathrm{O}_{7}, 343.0812$ ) (Supplementary Figure 17). ${ }^{1} \mathrm{H}$ NMR $\left(600 \mathrm{MHz}, \mathrm{DMSO}-d_{6}\right)$ and ${ }^{13} \mathrm{C}$ NMR $\left(150 \mathrm{MHz}, \mathrm{DMSO}-d_{6}\right)$ data, see Table 2 and Supplementary Figures 18, 19.

\section{Synthesis of Compounds 20-22}

Compound 5 ( $1 \mathrm{~g}, 3.0 \mathrm{mmol})$ was dissolved in $\mathrm{CH}_{2} \mathrm{Cl}_{2}(100 \mathrm{~mL})$, and $\mathrm{BBr}_{3}\left(27 \mathrm{~mL}, 18 \mathrm{mmol}, 17 \%\right.$ in $\left.\mathrm{CH}_{2} \mathrm{Cl}_{2}\right)$ was added at $-20^{\circ} \mathrm{C}$ under the argon atmosphere. After stirring overnight at $\mathrm{rt}, \mathrm{H}_{2} \mathrm{O}(40 \mathrm{~mL})$ was added to quench the reaction at $0^{\circ} \mathrm{C}$. The $\mathrm{CH}_{2} \mathrm{Cl}_{2}$ was evaporated and then EtOAc $(200 \mathrm{~mL})$ was added. The EtOAc phase was washed with $\mathrm{H}_{2} \mathrm{O}(20 \mathrm{~mL} \times 4)$ and concentrated in vacuo. The residue was dissolved in $\mathrm{MeOH}$ (50 mL), and silica gel (200-300 mesh, $20 \mathrm{~g})$ was added to the solution. The reaction mixture was stirred overnight at $\mathrm{rt}$ and then the solvent was evaporated in vacuo. The residue was purified by FCC eluting with EtOAc- $\mathrm{CH}_{2} \mathrm{Cl}_{2}$ (v/v 1:1) to provide compound 20 (550 mg, $1.78 \mathrm{mmol}, 59 \%$ yield) as a dark red 
TABLE $2 \mid{ }^{1} \mathrm{H}(600 \mathrm{MHz})$ and ${ }^{13} \mathrm{C}(150 \mathrm{MHz})$ NMR data of compounds 1, 18, and 19 in DMSO- $d_{6}$.

\begin{tabular}{|c|c|c|c|c|c|c|}
\hline \multirow[t]{2}{*}{ Position } & \multicolumn{2}{|c|}{1} & \multicolumn{2}{|c|}{18} & \multicolumn{2}{|c|}{19} \\
\hline & $\delta_{c}$ & $\delta_{H}(\boldsymbol{J} \text { in } \mathrm{Hz})^{\mathrm{a}}$ & $\delta_{c}$ & $\delta_{H}(J$ in $\mathrm{Hz})$ & $\delta_{c}$ & $\delta_{H}(\boldsymbol{J}$ in $\mathrm{Hz})$ \\
\hline 1 & 126.5, C & & 125.7, C & & 125.7, C & \\
\hline 2 & 115.0, $\mathrm{CH}$ & $6.88, d(1.8)$ & 118.6, CH & $6.75, d(2.0)$ & 118.6, CH & $6.74, d(2.0)$ \\
\hline 3 & 148.2, C & & 143.8, C & & 143.7, C & \\
\hline 4 & 146.7, C & & 144.3, C & & 144.2, C & \\
\hline 5 & $112.5, \mathrm{CH}$ & 6.96, d (8.3) & $114.8, \mathrm{CH}$ & $6.71, d(8.0)$ & $114.8, \mathrm{CH}$ & $6.71, d(8.0)$ \\
\hline 6 & 123.1, CH & 6.82, dd $(8.3,1.8)$ & 122.0, CH & $6.60, \mathrm{dd}(8.0,2.0)$ & 122.0, CH & $6.59, \mathrm{dd}(8.0,1.9)$ \\
\hline $1^{\prime}$ & 117.7, C & & 116.0, C & & 115.8, C & \\
\hline $2^{\prime}$ & 148.3, C & & 145.0, C & & $144.9, \mathrm{C}$ & \\
\hline $3^{\prime}$ & $139.5, \mathrm{C}$ & & $134.4, \mathrm{C}$ & & $134.4, \mathrm{C}$ & \\
\hline $4^{\prime}$ & 132.7, C & & 129.6, C & & 130.1, C & \\
\hline $5^{\prime}$ & 103.2, CH & $6.46, \mathrm{~s}$ & 106.5, CH & $6.26, \mathrm{~s}$ & 106.5, CH & $6.24, \mathrm{~s}$ \\
\hline $6^{\prime}$ & 153.2, C & & 148.2, C & & 148.1, C & \\
\hline $1^{\prime \prime}$ & $138.2, \mathrm{C}$ & & 128.2, C & & 128.2, C & \\
\hline $2^{\prime \prime}$ & $128.7, \mathrm{CH}$ & $7.61, \mathrm{~d}(7.5)$ & $130.0, \mathrm{CH}$ & $7.35, d(8.5)$ & 116.6, CH & $6.97, d(2.0)$ \\
\hline $3^{\prime \prime}$ & $128.4, \mathrm{CH}$ & $7.47, \mathrm{t}(7.5)$ & $114.9, \mathrm{CH}$ & $6.79, d(8.5)$ & 144.7, C & \\
\hline $4^{\prime \prime}$ & 127.3, CH & $7.37, \mathrm{t}(7.5)$ & 156.2, C & & 144.2, C & \\
\hline $5^{\prime \prime}$ & $128.4, \mathrm{CH}$ & $7.47, \mathrm{t}(7.5)$ & $114.9, \mathrm{CH}$ & $6.79, d(8.5)$ & 115.3, CH & $6.75, d(8.0)$ \\
\hline $6^{\prime \prime}$ & 128.7, CH & $7.61, \mathrm{~d}(7.5)$ & 130.0, CH & $7.35, d(8.5)$ & 119.9, CH & 6.79 , dd $(8.0,2.0)$ \\
\hline $1^{\prime \prime \prime}$ & $64.8, \mathrm{CH}_{2}$ & $4.53, d(6.7)$ & & & & \\
\hline $2^{\prime \prime \prime}$ & $120.4, \mathrm{CH}$ & $5.47, \mathrm{t}(6.7)$ & & & & \\
\hline $3^{\prime \prime \prime}$ & $136.9, \mathrm{C}$ & & & & & \\
\hline $4^{\prime \prime \prime}$ & $18.0, \mathrm{CH}_{3}$ & $1.72, \mathrm{~s}$ & & & & \\
\hline $5^{\prime \prime \prime}$ & $25.5, \mathrm{CH}_{3}$ & $1.76, \mathrm{~s}$ & & & & \\
\hline 3-OMe & $55.5, \mathrm{CH}_{3}$ & $3.73, \mathrm{~s}$ & & & & \\
\hline $3^{\prime}$-OMe & $60.4, \mathrm{CH}_{3}$ & $3.30, \mathrm{~s}$ & & & & \\
\hline 6'-OMe & 55.7, $\mathrm{CH}_{3}$ & $3.67, \mathrm{~s}$ & & & & \\
\hline $2^{\prime}-\mathrm{OH}$ & & $8.68, \mathrm{~s}$ & & & & \\
\hline
\end{tabular}

${ }^{a} d, d d, s$, t respectively means doublet, a doublet of doublets, singlet and triplet.

solid $\left(R_{f} 0.2\right)$. By the same procedures, compound 21 (389 mg, $1.2 \mathrm{mmol}, 86 \%$ yield, $\left.R_{f} 0.2\right)$ was prepared from the reaction of compound 6 (500 mg, $1.4 \mathrm{mmol})$ with $\mathrm{BBr}_{3}(12.7 \mathrm{~mL}, 8.4 \mathrm{mmol})$ in $\mathrm{CH}_{2} \mathrm{Cl}_{2}$ and then 200-300 mesh silica gel (12 g) in $\mathrm{MeOH}$, and purified by FCC eluting with EtOAc- $\mathrm{CH}_{2} \mathrm{Cl}_{2}$ (v/v 2:1), while compound 22 (58 mg, $0.17 \mathrm{mmol}, 63 \%$ yield, $R_{f} 0.3$ ) was prepared from the reaction of compound $7(100 \mathrm{mg}, 0.27 \mathrm{mmol})$ with $\mathrm{BBr}_{3}$ (2.4 mL, $1.62 \mathrm{mmol}$ ) in $\mathrm{CH}_{2} \mathrm{Cl}_{2}$ and then $200-300$ mesh silica gel $(6 \mathrm{~g})$ in $\mathrm{MeOH}$, and purified by FCC eluting with EtOAc- $\mathrm{CH}_{2} \mathrm{Cl}_{2}$ (v/v 4:1).

Compound 20: ${ }^{1} \mathrm{H}$ NMR (600 MHz, DMSO- $\left.d_{6}\right)$ and ${ }^{13} \mathrm{C}$ NMR (150 MHz, DMSO- $d_{6}$ ) data, see Supplementary Table 6 and Supplementary Figures 20, 21. ESIMS $m / z$ 307.1 $[\mathrm{M}-\mathrm{H}]^{-}$.

Compound 21: IR (KBr) $\nu_{\max } 3122,2359,2339,1653,1602$, $1510,1404,1335,1281,1228,1176,1101,841,667,538 \mathrm{~cm}^{-1}$. HR ESIMS $m / z 325.0704[\mathrm{M}+\mathrm{H}]^{+}$(calcd. for $\mathrm{C}_{18} \mathrm{H}_{13} \mathrm{O}_{6}, 325.0707$ ) (Supplementary Figure 22). ${ }^{1} \mathrm{H}$ NMR (600 MHz, DMSO- $d_{6}$ ) and ${ }^{13} \mathrm{C}$ NMR $\left(150 \mathrm{MHz}, \mathrm{DMSO}-d_{6}\right)$ data, see Table 3 and Supplementary Figures 23, 24.

Compound 22: IR (KBr) $\nu_{\max } 3417,3130,2357,2333,1655$, $1618,1552,1506,1281,1201,1099,933,876,820,779,667 \mathrm{~cm}^{-1}$. HR ESIMS $m / z 341.0649[\mathrm{M}+\mathrm{H}]^{+}$(calcd. for $\mathrm{C}_{18} \mathrm{H}_{13} \mathrm{O}_{7}$, 341.0656) (Supplementary Figure 25). ${ }^{1} \mathrm{H}$ NMR (600 MHz,
DMSO- $\left.d_{6}\right)$ and ${ }^{13} \mathrm{C}$ NMR $\left(150 \mathrm{MHz}\right.$, DMSO- $\left.d_{6}\right)$ data, see Table 3 and Supplementary Figures 26, 27.

\section{Synthesis of Compounds 23-25}

Compound $5(30 \mathrm{mg}, 89 \mu \mathrm{mol})$ was dissolved in $\mathrm{CH}_{2} \mathrm{Cl}_{2}$ $(3 \mathrm{~mL})$, then DMAP (102 $\mathrm{mg}, 0.8 \mathrm{mmol})$ and acetic anhydride $(0.08 \mathrm{~mL}, 0.8 \mathrm{mmol})$ were added sequentially. After stirring for $2 \mathrm{~h}$ at $40^{\circ} \mathrm{C}$, the $\mathrm{CH}_{2} \mathrm{Cl}_{2}$ was evaporated and EtOAc $(20 \mathrm{~mL})$ was added. The obtained organic phase was washed with $\mathrm{H}_{2} \mathrm{O}(20 \mathrm{~mL} \times 4)$, dried over anhydrous $\mathrm{Na}_{2} \mathrm{SO}_{4}$, and concentrated in vacuo. The residue was purified by SepaBean machine eluting with $5-70 \% \mathrm{MeOH} / \mathrm{H}_{2} \mathrm{O}$ to provide 23 (36 mg, $78 \mu \mathrm{mol}, 88 \%$ yield) as a white solid. By the same procedures, compounds 24 (35 mg, $67 \mu \mathrm{mol}, 79 \%$ yield) and 25 (38 mg, $66 \mu \mathrm{mol}, 81 \%$ yield) were, respectively, prepared from the reaction of compound $6(30 \mathrm{mg}, 85 \mu \mathrm{mol})$ with DMAP (124 mg, $1.02 \mathrm{mmol})$ and acetic anhydride $(0.1 \mathrm{~mL}$, $1.02 \mathrm{mmol})$ in $\mathrm{CH}_{2} \mathrm{Cl}_{2}(3 \mathrm{~mL})$, and compound 7 (30 mg, $81 \mu \mathrm{mol})$ with DMAP (148 mg, $1.21 \mathrm{mmol})$ and acetic anhydride (0.12 mL, $1.21 \mathrm{mmol})$ in $\mathrm{CH}_{2} \mathrm{Cl}_{2}(3 \mathrm{~mL})$. Both compounds 24 and 25 were purified by SepaBean machine eluting with $5-65 \% \mathrm{MeOH} / \mathrm{H}_{2} \mathrm{O}$. 
TABLE 3 | ${ }^{1} \mathrm{H}(600 \mathrm{MHz})$ and ${ }^{13} \mathrm{C}(150 \mathrm{MHz})$ NMR data of compounds 21, 22, and 25 in DMSO- $d_{6}$.

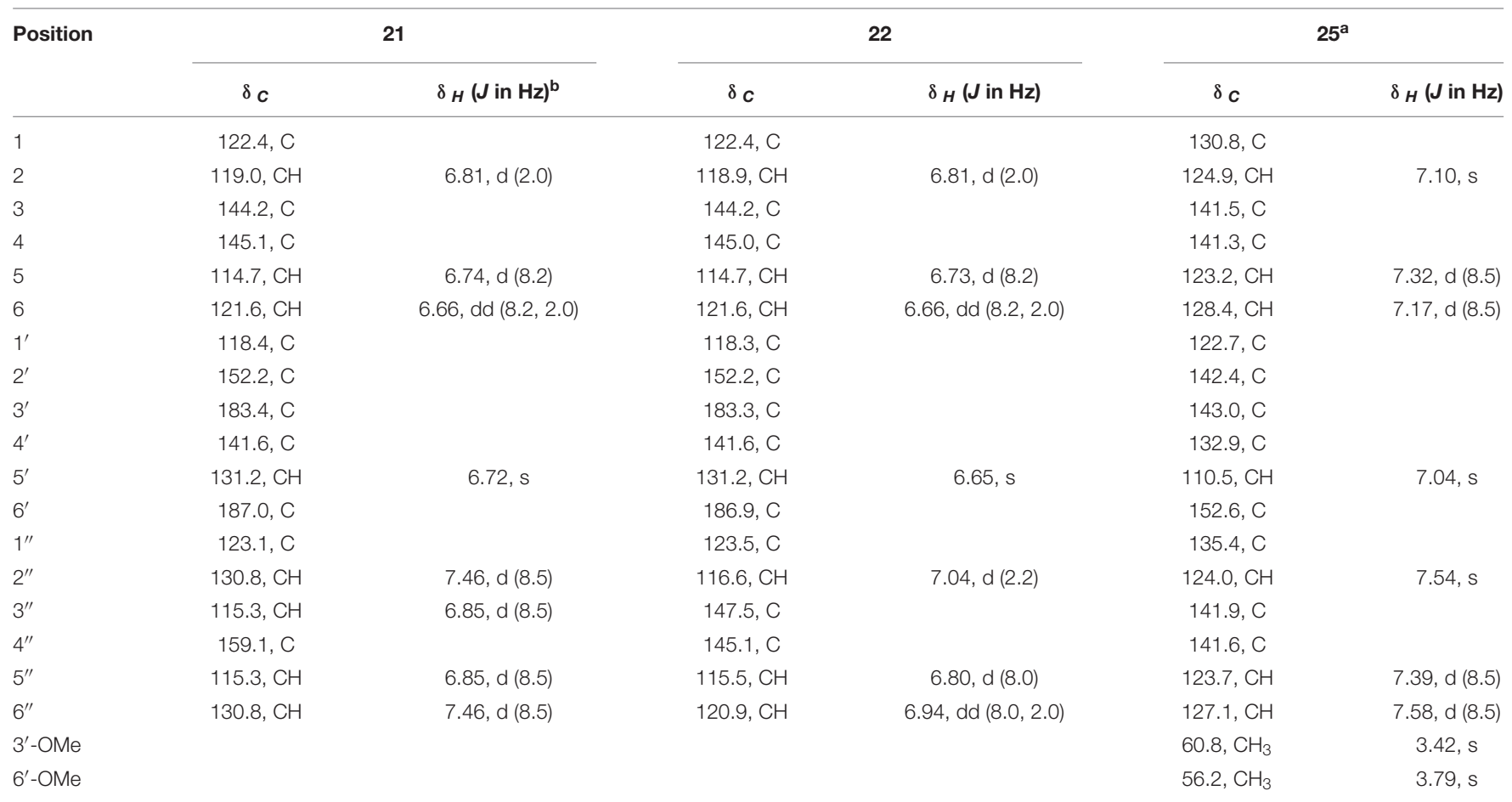

${ }^{a}$ The ${ }^{1} \mathrm{H}$ and ${ }^{13} \mathrm{C}$ NMR Data for five acetoxy were $\delta_{H} 2.06$ (s, 3H), $2.29(\mathrm{~s}, 3 \mathrm{H}), 2.31$ (s, 9H), and $\delta_{\mathrm{C}} 168.3 \times 2(\mathrm{C}), 168.4 \times 2(\mathrm{C}), 168.7(\mathrm{C}), 20.0(\mathrm{CH}), 20.4 \times 4$ $\left(\mathrm{CH}_{3}\right)$, respectively. ${ }^{b} d, d d$, s respectively means doublet, a doublet of doublets, and singlet.

Compound 23: IR (KBr) v $v_{\max } 3132,2356,2333,1761,1653$, $1562,1522,1479,1396,1228,1201,1667,1107,1082,1009$, $920,841,671 \mathrm{~cm}^{-1}$. HR ESIMS $\mathrm{m} / z 465.1537[\mathrm{M}+\mathrm{H}]^{+}$(calcd. for $\mathrm{C}_{26} \mathrm{H}_{25} \mathrm{O}_{8}, 465.1544$ ) (Supplementary Figure 28). ${ }^{1} \mathrm{H}$ NMR $\left(600 \mathrm{MHz}, \mathrm{DMSO}-d_{6}\right)$ and ${ }^{13} \mathrm{C}$ NMR $\left(150 \mathrm{MHz}\right.$, DMSO- $\left.d_{6}\right)$ data, see Supplementary Table 6 and Supplementary Figures 29, 30.

Compound 24: ${ }^{1} \mathrm{H}$ NMR $\left(600 \mathrm{MHz}\right.$, DMSO- $\left.d_{6}\right)$ and ${ }^{13} \mathrm{C}$ NMR $\left(150 \mathrm{MHz}, \mathrm{DMSO}-d_{6}\right)$ data, see Supplementary Table 6 and Supplementary Figures 31, 32. ESIMS $m / z 545.0[\mathrm{M}+\mathrm{Na}]^{+}$.

Compound 25: IR (KBr) $v_{\max } 3128,2359,2337,1768,1655$, $1558,1522,1475,1400,1203,1115,1093,899,671 \mathrm{~cm}^{-1}$. HR ESIMS $m / z 603.1470[\mathrm{M}+\mathrm{Na}]^{+}$(calcd. for $\mathrm{C}_{30} \mathrm{H}_{28} \mathrm{O}_{12} \mathrm{Na}$, 603.1473) (Supplementary Figure 33). ${ }^{1} \mathrm{H}$ NMR $(600 \mathrm{MHz}$, DMSO- $d_{6}$ ) and ${ }^{13} \mathrm{C}$ NMR $\left(150 \mathrm{MHz}\right.$, DMSO- $\left.d_{6}\right)$ data, see Table 3 and Supplementary Figures 34, 35.

\section{Oxygen Radical Absorbance Capacity (ORAC) Assay}

The anti-oxidative activity of compounds was evaluated by ORAC assay (Huang et al., 2002) that was carried out mainly by using 2,2'-azobis(2-amidinopropane) dihydrochloride (AAPH, $153.0 \mu \mathrm{M}$ ), fluorescein (FL, 81.6 $\mathrm{nM}$ ), testing compounds, and trolox as a positive control, all of which were dissolved in phosphate buffer solution (PBS, $75 \mathrm{mM}, \mathrm{pH}$ 7.4). The concentrations were $6.25 \mu \mathrm{M}$ for compounds 4-7 and trolox, $12.5 \mu \mathrm{M}$ for compounds $\mathbf{1 - 3 , 8 - 1 6}$ and trolox, and $25.0 \mu \mathrm{M}$ for compounds 17-25 and trolox, respectively (Supplementary Figure 36). In short, each $25 \mu \mathrm{L}$ of testing compounds, blank (PBS), negative (PBS) and trolox, and $150 \mu \mathrm{L}$ of FL were added in each well and incubated at $37^{\circ} \mathrm{C}$ for $10 \mathrm{~min}$. Each $25 \mu \mathrm{L}$ of AAPH was then added to the testing compounds, blank and trolox groups, and $25 \mu \mathrm{L}$ of PBS was added to the negative group. Fluorescence intensity of each well was measured one time every 1 min for 90 cycles using a Fluoroskan Ascent FL plate-reader (Thermo Scientific Varioskan LUX) at excitation of $\lambda 485 \mathrm{~nm}$ and emission of $\lambda 530 \mathrm{~nm}$. The relative fluorescence intensity $f$ was equaled to the ratio of the absolute fluorescence reading to the initial fluorescence reading, and the net area under curve (AUC) was obtained by subtracting the AUC of the blank from that of the compound. The AUC was calculated as $0.5+f_{1}+\ldots f_{i}+\ldots$ $+f_{89}+0.5 \times f_{90}$, in which $f_{i}$ means the ratio of fluorescence reading at time $i$ to the initial fluorescence reading. The final ORAC values were calculated as micromole of trolox equivalents per micromole of the compound ( $\mu$ mole TE/ $\mu$ mole) by using a regression equation between the trolox concentration and the net area under the FL decay curve. That is, the relative ORAC value $=\left(\mathrm{AUC}_{\text {compound }}-\mathrm{AUC}_{\text {blank }}\right) /\left(\mathrm{AUC}_{\text {trolox }}-\mathrm{AUC}_{\text {blank }}\right)$.

\section{DPPH Radical-Scavenging Assay}

The anti-oxidative activity of compounds was also evaluated by 2,2-diphenyl-1-picrylhydrazyl (DPPH) radical-scavenging assay (Wang et al., 2007). The experiment was divided into the following five groups, blank (methanol, $\mathrm{MeOH}$ ), sample (mix compound and DPPH solution), background (pure compound solution), negative (pure DPPH solution), and positive [mix vitamin C (VC) and DPPH solution] controls. DPPH (0.15 mM), compounds $(1-100 \mu \mathrm{M})$, and VC $(1-100 \mu \mathrm{M})$ that was regarded as a compound sample in the following procedures all were 
dissolved in $\mathrm{MeOH}$. Each $160 \mu \mathrm{L}$ of $\mathrm{MeOH}$ was placed in negative control and blank groups, while each $160 \mu \mathrm{L}$ of testing compounds or VC was placed in sample and background groups. Then, $\mathrm{MeOH}$ (each $40 \mu \mathrm{L}$ ) was, respectively, added to blank and background groups, while $40 \mu \mathrm{L}$ of DPPH was, respectively, added to negative, positive, and sample controls. After 30-min incubation in the dark at $\mathrm{rt}$, the decrease in $\mathrm{DPPH}$ radical concentration was monitored by measuring the absorbance at $\lambda$ $517 \mathrm{~nm}$ with a microplate reader (Multiskan Spectrum, Thermo Scientific Varioskan LUX). The DPPH radical-scavenging rate was calculated as:

$$
\begin{aligned}
\text { Scavenging rate }(\%)= & {\left[\left(A_{\text {negative }}-A_{\text {blank }}\right)\right.} \\
- & \left.\left(A_{\text {sample }}-A_{\text {background }}\right)\right] / \\
& \left(A_{\text {negative }}-A_{\text {blank }}\right) \times 100 \% .
\end{aligned}
$$

The $\mathrm{IC}_{50}$ (half maximal inhibitory concentration) values of compounds and VC were calculated by SPSS (Statistical Package for the Social Sciences) software from the radical-scavenging rates at the final concentrations of $100,50,10,5$, and $1 \mu \mathrm{M}$.

\section{$\alpha$-Glucosidase Inhibitory Assays $\alpha$-Glucosidase Inhibitions in Saccharomyces cerevisiae}

The inhibitions of the compounds against $\alpha$-glucosidase from Saccharomyces cerevisiae were assayed by reported method (Xu et al., 2018). The testing compounds were dissolved in dimethyl sulfoxide (DMSO) to obtain stock solution (10 mM) and then diluted into the concentrations by $\mathrm{PBS}(\mathrm{pH} 6.8)$, while $\alpha$-glucosidase (2.0 U/mL, Sigma), 4-nitrophenyl- $\alpha$-Dglucopyranoside (PNPG, $2.5 \mathrm{mM}$, Macklin), $\mathrm{Na}_{2} \mathrm{CO}_{3}(0.2 \mathrm{M})$, and acarbose $(2.5 \mathrm{mg} / \mathrm{mL}$, Sigma) were directly dissolved in PBS. $20 \mu \mathrm{L}$ of the compound solution and acarbose were, respectively, mixed in a 96-well microplate with $20 \mu \mathrm{L}$ of $\alpha$-glucosidase and $60 \mu \mathrm{L}$ of PBS as the drug and positive groups, while the pure PBS solution was used as the blank group. After incubation for $15 \mathrm{~min}$ at $37^{\circ} \mathrm{C}, 20 \mu \mathrm{L}$ of PNPG solution was added to each well of testing groups and further incubated at $37^{\circ} \mathrm{C}$ for $30 \mathrm{~min}$. Finally, $80 \mu \mathrm{L}$ of $\mathrm{Na}_{2} \mathrm{CO}_{3}$ solution was added to each well to stop the reaction and the absorbance was measured by a microplate reader (Multiskan Spectrum, Thermo Scientific Varioskan LUX) at $\lambda 405 \mathrm{~nm}$. The inhibitory rate $(\%)$ was calculated as $\left[1-\left(\mathrm{A}_{\text {drug }} / \mathrm{A}_{\text {blank }}\right)\right] \times 100 \%$. The $\mathrm{IC}_{50}$ values were calculated by SPSS software from the drug inhibitory rates at the final concentrations of 500, 250, 50, 25, 5, and $1 \mu \mathrm{M}$ (Table 3 ).

\section{$\alpha$-Glucosidase Inhibitions in Caco-2 Cell Line}

The $\alpha$-glucosidase inhibition assay was also carried out in caco2 cell line (Hansawasdi and Kawabata, 2006). Caco-2 cells at logarithmic growth stage were inoculated in a 6-well plate with an inoculation density of $4000 / \mathrm{cm}^{2}$ and cultured in an incubator with $5 \% \mathrm{CO}_{2}$ at $37^{\circ} \mathrm{C}$ in a Dulbecco's Modified Eagle Medium (DMEM) supplemented with $10 \%$ fetal bovine serum, $1 \%$ non-essential amino acid, $1 \%$ penicillin/streptomycin, $1 \%$ L-glutamine, and $0.25 \mathrm{mg}$ plasmocin. The DMEM medium was changed one time every 2 days for 24 days. Then, the culture medium was removed, and the cell surface was washed three times by a PBS solution ( $\mathrm{pH} 7.4$ ) at $37^{\circ} \mathrm{C} .1 .0 \mathrm{~mL}$ of sucrose/maltose (both $28 \mathrm{mM}$ ) PBS solution was added to the control well, $1 \mathrm{~mL}$ of PBS was added to the blank well, $0.2 \mathrm{~mL}$ of compounds or acarbose (positive control) with different concentration and $0.8 \mathrm{~mL}$ of above sucrose/maltose solution were added to the drug well. The final concentration gradients of compounds and acarbose were 1.0, 0.3, 0.1, 0.03, $0.01 \mu \mathrm{M}$ and $10000,3000,1000,300,100 \mu \mathrm{g} / \mathrm{mL}$, respectively. The obtained solutions for the enzymatic hydrolysis reactions of sucrose and maltose were incubated at $37^{\circ} \mathrm{C}$ for $60 \mathrm{~min}$. After terminating the reactions in an ice bath for $10 \mathrm{~min}$, $10 \mu \mathrm{L}$ of the reaction mixture was added into $1 \mathrm{~mL}$ of the glucose kit (Nanjing Jiancheng Bioengineering Institute Co., Ltd.) and maintain $10 \mathrm{~min}$ at $37^{\circ} \mathrm{C}$. The $\alpha$-glucosidase inhibitory activity of the compounds was then determined by measuring the glucose content in the reaction solution (pipette $100 \mu \mathrm{L}$ reaction solution into 96-well plate) via the absorbance at $\lambda 505 \mathrm{~nm}$ with a microplate reader (BioTek Synergy H1, BioTek, VT, United States). The $\alpha$-glucosidase inhibitory rate $(\%)$ was calculated as $\left[1-\left(\mathrm{A}_{\text {drug }}-\mathrm{A}_{\text {blank }}\right) /\right.$ $\left.\left(\mathrm{A}_{\text {control }}-\mathrm{A}_{\text {blank }}\right)\right] \times 100 \%$. The $\mathrm{IC}_{50}$ values were calculated as showed in Table 3 by SPSS software.

The cytotoxic effects on the coca- 2 cells were evaluated by the CTG assay (Elisia and Kitts, 2008; Wang et al., 2019). Briefly, coca- 2 cells were seeded in 96-well plates at a density of $2 \times 10^{3}$ cells/well and treated with the final concentration of $1.0 \mu \mathrm{M}$ of the compounds. After $72 \mathrm{~h}$ incubation, $100 \mu \mathrm{L}$ of CTG solution (Promega) was added into each well. The luminescence value was tested by using a microplate reader (BioTek Synergy H1) after staying at $\mathrm{rt}$ for $10 \mathrm{~min}$.

\section{RESULTS AND DISCUSSION}

\section{Metabolic Regulation of the Fungus}

After adding the leaves of Eucommia ulmoides in the rice medium, both the production and the $\alpha$-glucosidase inhibitory activity of the EtOAc extracts of the solid-state fermentation increased significantly from 5.3 to $9.5 \mathrm{~g} / \mathrm{kg}$ and from the $\mathrm{IC}_{50}$ value of 15.0 to $2.0 \mu \mathrm{g} / \mathrm{mL}$, respectively. The original $p$-terphenyl products 5-7, 10, and 12 in the rice medium also largely increased by adding the leaves of E. ulmoides. In addition, the number of the $p$-terphenyl-type chromophores also increased significantly. For example, p-terphenyls 1-4, 8, 9, 11, and 13-16 were newly produced after adding the leaves of E. ulmoides (Figure 1). The results indicated that the content and diversity of the microbial natural products could increase highly by adding the host materials to the culture media of the microorganisms via the chemical microbehost interaction.

\section{The Identification of the New p-Terphenyl (1)}

Compound 1 was obtained as a white powder. Its molecular formula was determined as $\mathrm{C}_{26} \mathrm{H}_{28} \mathrm{O}_{5}$ according to its HR-ESIMS peak at $m / z$ 443.1837 $[\mathrm{M}+\mathrm{Na}]^{+}$(Supplementary Figure 2). 


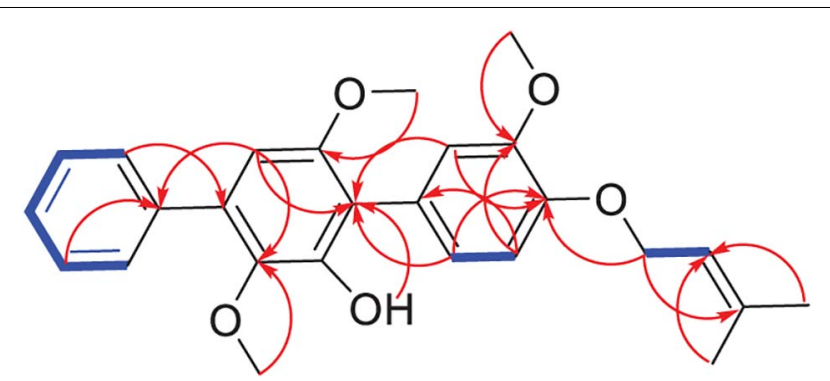

FIGURE 3 | Key HMBC (red arrows) and COSY (blue bold lines) of compound $\mathbf{1}$.

The NMR spectra displayed nine $\mathrm{sp}^{2}$ - non-hydrogenated carbons, ten $\mathrm{sp}^{2}$-methines, one $\mathrm{sp}^{3}$-methylene, three methoxyls, and two methyls (Supplementary Figures 35). Except for the lack of $4^{\prime \prime}$-hydroxyl, these data (Table 2) were very similar to those reported 3-methoxyterprenin (13), indicating compound $\mathbf{1}$ as a highly oxygenated p-terphenyl. The signals of five mono-substituted phenyl protons at $\delta_{H} 7.61\left(\mathrm{~d}, J=7.5 \mathrm{~Hz}, \mathrm{H}-2^{\prime \prime} / \mathrm{H}-6^{\prime \prime}\right), 7.47(\mathrm{t}$, $\left.J=7.5 \mathrm{~Hz}, \mathrm{H}-3^{\prime \prime} / \mathrm{H}-5^{\prime \prime}\right)$, and $7.37\left(\mathrm{t}, J=7.5 \mathrm{~Hz}, \mathrm{H}-4^{\prime \prime}\right)$ which showed ${ }^{1} \mathrm{H}^{1} \mathrm{H}$ COSY correlations (Figure 3 and Supplementary Figure 6) of $\mathrm{H}-2^{\prime \prime} / \mathrm{H}-3^{\prime \prime} / \mathrm{H}-4^{\prime \prime}$ confirmed replacement of $4^{\prime \prime}-\mathrm{OH}$ in $\mathbf{1 3}$ by a hydrogen atom in $\mathbf{1}$. Furthermore, the ${ }^{1} \mathrm{H}-{ }^{1} \mathrm{H}$ COSY between $\mathrm{H}-5 \quad\left(\delta_{H}\right.$ 6.96) and H-6 ( $\delta_{H}$ 6.82), H-1"' $\left(\delta_{H}\right.$ 4.53) and $\mathrm{H}-2^{\prime \prime \prime}\left(\delta_{H}\right.$ 5.47), along with the key HMBC connections (Figure 3 and Supplementary Figure 7) from $\mathrm{H}-1^{\prime \prime \prime}$ to $\mathrm{C}-3^{\prime \prime \prime}\left(\delta_{C}\right.$ 136.9) and $\mathrm{C}-4\left(\delta_{C} 146.7\right), \mathrm{H}-4^{\prime \prime \prime}\left(\delta_{H} 1.72\right)$ to $\mathrm{C}-2^{\prime \prime \prime}\left(\delta_{C} 128.7\right)$ and $C-5^{\prime \prime \prime}\left(\delta_{C} 25.5\right)$, and $\mathrm{H}-2^{\prime \prime} / \mathrm{H}-6^{\prime \prime}$ to $\mathrm{C}-4^{\prime} \quad\left(\delta_{C}\right.$ 132.7) supported the structure. Thus, compound $\mathbf{1}$ was identified as 3-O-methyl-4" -deoxyterprenin.

\section{Synthesis of $p$-Terphenyls 17-25}

As shown in Scheme 1, compounds 17-19 were synthesized from compounds $5-7$ by demethylation reaction using $\mathrm{BBr}_{3}$, which were further transformed to compounds 20-22 by oxidation of air in the system of silica gel and $\mathrm{MeOH}$. The acetylation of compounds 5-7 provided compounds 23-25 by $\mathrm{Ac}_{2} \mathrm{O} / \mathrm{DMAP}$. It is interesting that compounds $\mathbf{1 5}$ and $\mathbf{1 6}$ could be synthesized from compounds 6 and 7 by an oxidative dehydrocyclization of air in the system of silica gel and $\mathrm{MeOH}$. But compound 5 cannot undergo the same reaction to form the corresponding $2,2^{\prime}$-oxygen bridged $p$-terphenyl derivative, indicating that the oxidative cyclization might be carried out by a radical process. That is, compounds $\mathbf{6}$ and 7 formed a radical intermediate a which underwent an intramolecular cyclization to generate the keto intermediate $\mathbf{b}$ in the presence of $\mathrm{SiO}_{2}$ and $\mathrm{O}_{2}$. Compounds $\mathbf{1 5}$ and $\mathbf{1 6}$ were then yielded by a keto-enol tautomerization of the intermediate $\mathbf{b}$ in the $\mathrm{SiO}_{2}$ and $\mathrm{MeOH}$ (Scheme 2). To confirm the effect of silica gel and $\mathrm{O}_{2}$, the reaction of compound 6 was carried out in the four conditions, i.e., $\mathrm{O}_{2}$, silica gel/argon, silica gel/air, and silica gel/ $\mathrm{O}_{2}$. The results showed that compound 6 could not be converted to compound $\mathbf{1 5}$ without silica gel. Both the reaction and conversion rates increased in the order of $\mathrm{O}_{2}$, silica gel/argon, silica gel/air, and silica gel/O ${ }_{2}$ (Supplementary Figure 37). And the silica gel acted as a catalyst to accelerate the tautomerization between keto and enol. The fact that a little compound $\mathbf{1 5}$ was also formed in the silica gel/argon system could be explained from the air adsorbed in the silica gel.

\section{The Bioactivities of $p$-Terphenyls}

All of the obtained $p$-terphenyls (1-25) were tested for the antioxidative activity against DPPH radicals and ORAC as well as the $\alpha$-glucosidase inhibitions. The results (Table 3 ) showed that compounds 4-7, 17, and 20 have a significant antioxidant capacity with the ORAC values of $6.8,6.0,5.7,4.5,4.8$, and $6.1 \mu$ mole TE/ $\mu$ mole, respectively, indicating that $4-, 2^{\prime}-$, and $4^{\prime \prime}$ hydroxys are active sites of $p$-terphenyls. When these hydroxyls were changed to hydrogens or etherified in part or wholly, the antioxidant capacity was greatly reduced. Compounds 4, 6, 7, $9,11,12,19,21$, and 22 showed more potent DPPH radicalscavenging activity than $\mathrm{VC}$ with the $\mathrm{IC}_{50}$ value of $1.7,1.4,1.1$, $1.6,1.6,1.8,1.6,1.7$, and $2.8(\mathrm{VC}) \mu \mathrm{M}$, respectively, indicating

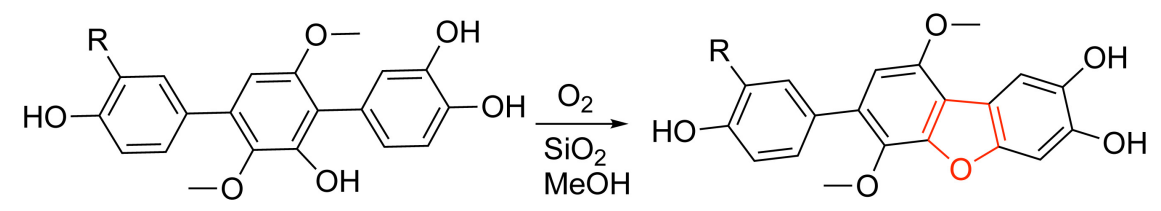<smiles>[R]c1cc(-c2cc(OC)c(C3=CC(=O)C(O)=CC3)c(O)c2OC)ccc1OCC(=O)O</smiles>

SCHEME 2 | A possible mechanism forming $\mathbf{1 5}$ and $\mathbf{1 6}$ by an oxidative cyclization of $\mathbf{6}$ and $\mathbf{7}$. 
that 4 - and $2^{\prime}$-hydroxys are very important active sites of the p-terphenyls. As the disappearance of the two hydroxys, changing to hydrogens, methoxyls or acetoxyls, for example, the DPPH radical-scavenging activity of $p$-terphenyls was greatly reduced. However, the activity is still maintained when the $2^{\prime}$-hydroxy formed a furan ring with C-6.

The most obvious inhibition against $\alpha$-glucosidase from Saccharomyces cerevisiae was observed for compounds 4, 5, 16, 20, and 21 whose $\mathrm{IC}_{50}$ values were $5.9,2.8,7.9,8.9$, and $4.0 \mu \mathrm{M}$, respectively. The results indicated that $4-, 2^{\prime}$,- and $4^{\prime \prime}$ hydroxys are the most important active-sites for $\alpha$-glucosidase inhibition of $p$-terphenyls, two or three of which were replaced by hydrogens, methoxyls or acetoxyls resulted in the loss or decrease of $\alpha$-glucosidase inhibitory activity. Seven compounds $(5-7,15,16,20$, and 21) with significant antioxidant and $\alpha$ glucosidase inhibitory activities could be prepared on a large scale, were further tested for the $\alpha$-glucosidase inhibitions in caco- 2 cell line. As expected, these seven compounds exhibited the announced activity with the $\mathrm{IC}_{50}$ values of $0.38,0.29,0.36$, $0.11,0.36,0.11$, and $0.12 \mu \mathrm{M}$, respectively. It is interesting that these seven compounds were not toxic to the caco- 2 cells at the concentration of $1 \mu \mathrm{M}$, whose inhibitory rate was $0.4 \%, 0.2 \%$, $0.5 \%, 20.5 \%, 2.7 \%, 0.4 \%$, and $1.2 \%$, respectively.

\section{CONCLUSION}

There is a mutually beneficial relationship between endophytes and their host plants. Adding the host plants to the culture medium of endophytes could enhanced the metabolic potential of the endophytic strains and thus enriched the chemodiversity of the microbial natural products. $p$-Terphenyls, especially those $4,2^{\prime}, 4^{\prime \prime}$-trihydroxy or $4,4^{\prime \prime}$-dihydroxy-1,2,1', $2^{\prime}$-furan substituted ones, have a stronger antioxidant activity, $\alpha$-glucosidase inhibitory activity and lower cytotoxicity, implying their

\section{REFERENCES}

Cai, S., Sun, S., Zhou, H., Kong, X., Zhu, T., Li, D., et al. (2011). Prenylated polyhydroxy-p-terphenyls from Aspergillus taichungensis ZHN-7-07. J. Nat. Prod. 74, 1106-1110. doi: 10.1021/np2000478

El-Elimat, T., Figueroa, M., Raja, H. A., Graf, T. N., Adcock, A. F., Kroll, D. J., et al. (2013). Benzoquinones and terphenyl compounds as phosphodiesterase4B inhibitors from a fungus of the order Chaetothyriales (MSX 47445). J. Nat. Prod. 76, 382-387. doi: 10.1021/np300749w

Elisia, I., and Kitts, D. D. (2008). Anthocyanins inhibit peroxyl radical-induced apoptosis in Caco-2 cells. Mol. Cell. Biochem. 312, 139-145. doi: 10.1007/ s11010-008-9729-1

Guo, Z. K., Yan, T., Guo, Y., Song, Y. C., Jiao, R. H., Tan, R. X., et al. (2012). pTerphenyl and diterpenoid metabolites from endophytic Aspergillus sp. YXf3. J. Nat. Prod. 75, 15-21. doi: 10.1021/np200321s

Hansawasdi, C., and Kawabata, J. (2006). $\alpha$-Glucosidase inhibitory effect of mulberry (Morus alba) leaves on caco-2. Fitoterapia 77, 568-573. doi: 10.1016/ j.fitote.2006.09.003

Huang, D., Ou, B., Hampsch-Woodill, M., Flanagan, J. A., and Prior, R. L. (2002). High-throughput assay of oxygen radical absorbance capacity (ORAC) using a multichannel liquid handling system coupled with a microplate fluorescence reader in 96-well format. J. Agric. Food Chem. 50, 4437-4444. doi: 10.1021/ jf0201529 potential use in the fight against diabetes as the drug leads or dietary supplements.

\section{DATA AVAILABILITY STATEMENT}

Publicly available datasets were analyzed in this study. This data can be found here: GenBank No. KY038594.

\section{AUTHOR CONTRIBUTIONS}

YX isolated the fungus and compounds, performed the structure elucidation, and assayed part of the bioactivity. YW synthesized the compounds. DW assayed part of the bioactivity. WH did fermentation and extraction. LW directed the implementation of the study and prepared the manuscript. WZ designed the study and revised the manuscript. All authors contributed to the article and approved the submitted version.

\section{FUNDING}

This work was supported by grants from the National Natural Science Foundation of China (Nos. 21867008 and U1812403), GMU [J(2020)006 and 19NSP078], the 100 Leading Talents of Guizhou Province for WZ, and Guizhou Provincial Engineering Research Center for Natural Drugs.

\section{SUPPLEMENTARY MATERIAL}

The Supplementary Material for this article can be found online at: https://www.frontiersin.org/articles/10.3389/fmicb. 2021.654963/full\#supplementary-material

Intaraudom, C., Bunbamrung, N., Dramae, A., Boonyuen, N., Kongsaeree, P., Srichomthong, K., et al. (2017). Terphenyl derivatives and drimanephathalide/isoindolinones from Hypoxylon fendleri BCC32408. Phytochemistry 139, 8-17. doi: 10.1016/j.phytochem.2017.03.008

Kamigauchi, T., Sakazaki, R., Nagashima, K., Kawamura, Y., Yasuda, Y., Matsushima, K., et al. (1998). Terprenins, novel immunosuppressants produced by Aspergillus candidus. J. Antibiot. 51, 445-450. doi: 10.7164/antibiotics.51.445

Karunakaran, U., and Park, K.-G. (2013). A systematic review of oxidative stress and safety of antioxidants in diabetes: focus on islets and their defense. Diabetes Metab. J. 37, 106-112. doi: 10.4093/dmj.2013.37.2.106

Kuhnert, E., Surup, F., Herrmann, J., Huch, V., Müller, R., and Stadler, M. (2015). Rickenyls A-E, antioxidative terphenyls from the fungus Hypoxylon rickii (Xylariaceae, Ascomycota). Phytochemistry 118, 68-73. doi: 10.1016/j. phytochem.2015.08.004

Li, W., Li, X. B., and Lou, H. X. (2018). Structural and biological diersity of natural pterphenyls. J. Asian. Nat. Prod. Res. 20, 1-13. doi: 10.1080/10286020.2017. 1381089

Lin, Y.-K., Xie, C.-L., Xing, C.-P., Wang, B.-Q., Tian, X.-X., Xia, J.-M., et al. (2019). Cytotoxic p-terphenyls from the deep-sea-derived Aspergillus candidus. Nat. Prod. Res. doi: 10.1080/14786419.2019.1633651 [Epub ahead of print].

Liu, J. K. (2006). Natural terphenyls: developments since 1877. Chem. Rev. 106, 2209-2223. doi: 10.1002/chin.200639247 
Liu, J. K., Hu, L., Dong, Z. J., and Hu, Q. (2004). DPPH radical scavenging activity of ten natural $p$-terphenyl derivatives obtained from three edible mushrooms indigenous to China. Chem. Biodivers. 1, 601-605. doi: 10.1002/ cbdv.200490050

Liu, S. S., Zhao, B. B., Lu, C. H., Huang, J. J., and Shen, Y. M. (2012). Two new p-terphenyl derivatives from the marine fungal strain Aspergillus sp. AF119. Nat. Prod. Commun. 7, 1057-1062.

Ma, K., Han, J., Bao, L., Wei, T., and Liu, H. (2014). Two sarcoviolins with antioxidative and $\alpha$-glucosidase inhibitory activity from the edible mushroom Sarcodon leucopus collected in Tibet. J. Nat. Prod. 77, 942-947. doi: 10.1021/ np401026b

Shan, T., Sun, J., Mao, Z., Mao, Z., Wang, S., Wang, Y., et al. (2019). Rapid separation and preparation method of symbiotic fungus Aspergillus sp. Bdf2 monomer compounds and application thereof. Faming Zhuanli Shenqing 2019:110283053A.

Takahashi, S., Suda, Y., Nakamura, T., Matsuoka, K., and Koshino, H. (2017). Total synthesis of kehokorins A-E, cytotoxic pterphenyls. J. Org. Chem. 82, 3159-3166. doi: 10.1021/ acs.joc.7b0 0147

Wang, D., Qu, P., Zhou, J., Wang, Y., Wang, L., and Zhu, W. (2020). pTerphenyl alcohols from a marine sponge-derived fungus, Aspergillus candidus OUCMDZ-1051. Mar. Life Sci. Technol. 2, 262-267. doi: 10.1007/s42995-02000039-x

Wang, D., Wang, Y., Ouyang, Y., Fu, P., and Zhu, W. (2019). Cytotoxic p-terphenyls from a marine-derived Nocardiopsis species. J. Nat. Prod. 82, 3504-3508. doi: 10.1021/acs.jnatprod.9b00963

Wang, S. M., Han, J. J., Ma, K., Jin, T., Bao, L., Pei, Y. F., et al. (2014). New $\alpha$-glucosidase inhibitors with $p$-terphenyl skeleton from the mushroom Hydnellum concrescens. Fitoterapia 98, 149-155. doi: 10.1016/j.fitote.2014.07. 019

Wang, W.-L., Zhu, T.-J., Tao, H.-W., Lu, Z.-Y., Fang, Y.-C., Gu, Q.-Q., et al. (2007). Three novel, structurally unique spirocyclic alkaloids from the halotolerant
B-17 fungal strain of Aspergillus variecolor. Chem. Biodivers 4, 2913-2919. doi: 10.1002/cbdv.200790240

Wei, H., Inada, H., Hayashi, A., Higashimoto, K., Pruksakorn, P., Kamada, S., et al. (2007). Prenylterphenyllin and its dehydroxyl analogs, new cytotoxic substances from a marine-derived fungus Aspergillus candidus IF10. J. Antibiot. 60, 586-590. doi: 10.1038/ja.2007.75

Xu, Y., Wang, C., Liu, H., Zhu, G., Fu, P., Wang, L., et al. (2018). Meroterpenoids and isocoumarinoids from a Myrothecium fungus associated with Apocynum venetum. Mar. Drugs 16:363. doi: 10.3390/md16100363

Yan, W., Li, S. J., Guo, Z. K., Zhang, W. J., and Wei, W. (2017). New p-terphenyls from the endophytic fungus Aspergillus sp. YXf3. Bioorg. Med. Chem. Lett. 27, 51-54. doi: 10.1016/j.bmcl.2016.11.033

Yonezawa, S., Komurasaki, T., Kawada, K., Tsuri, T., Fuji, M., Kugimiya, A., et al. (1998). Total synthesis of terprenin, a novel immunosuppressive p-terphenyl derivative. J. Org. Chem. 63, 5831-5837. doi: 10.1021/jo98 $0349 \mathrm{t}$

Zhang, X. Q., Mou, X. F., Mao, N., Hao, J. J., Liu, M., Zheng, J. Y., et al. (2018). Design, semisynthesis, $\alpha$-glucosidase inhibitory, cytotoxic, and antibacterial activities of p-terphenyl derivatives. Eur. J. Med. Chem. 146, 232-244. doi: 10.1016/j.ejmech.2018.01.057

Conflict of Interest: The authors declare that the research was conducted in the absence of any commercial or financial relationships that could be construed as a potential conflict of interest.

Copyright (c) $2021 \mathrm{Xu}$, Wang, Wu, He, Wang and Zhu. This is an open-access article distributed under the terms of the Creative Commons Attribution License (CC BY). The use, distribution or reproduction in other forums is permitted, provided the original author(s) and the copyright owner(s) are credited and that the original publication in this journal is cited, in accordance with accepted academic practice. No use, distribution or reproduction is permitted which does not comply with these terms. 